\title{
Detection of DNA mutations associated with mitochondrial diseases by Agilent 2100 bioanalyzer
}

\author{
Ching-You Lu ${ }^{a}$, Dan-Ju Tso ${ }^{a}$, Tom Yang ${ }^{b}$, Yuh-Jyh Jong ${ }^{c}$, Yau-Huei Wei ${ }^{\text {a,* }}$ \\ ${ }^{a}$ Department of Biochemistry and Center for Cellular and Molecular Biology, School of Life Science, National Yang-Ming University, \\ Taipei, Taiwan 112, ROC \\ ${ }^{\mathrm{b}}$ CAG Sector of Agilent Technologies, Taiwan, Ltd., Taipei, Taiwan 105, ROC \\ ${ }^{\mathrm{c}}$ Departments of Clinical Laboratory and Pediatrics, Kaohsiung Medical University Hospital, Kaohsiung, \\ Taiwan 807, ROC
}

Received 9 October 2001; received in revised form 4 December 2001; accepted 6 December 2001

\begin{abstract}
Background: Molecular analysis of mitochondrial DNA (mtDNA) has provided a final diagnosis for many of the mitochondrial diseases. We evaluated the Agilent 2100 bioanalyzer (Agilent Technologies, Palo Alto, CA) to determine whether the system could replace the conventional restriction fragment length polymorphism (RFLP) analysis by the agarose gel electrophoresis for the detection of the mtDNA mutation. Methods: Three members of a family with MELAS syndrome and four members of a family with MERRF syndrome were recruited for this study. After PCR and restriction enzyme digestion, DNA fragments were separated on the Agilent 2100 bioanalyzer in conjunction with the DNA 500 and DNA 1000 Labchip kits and by electrophoresis on precast 3\% agarose gels. Results: The data generated by the DNA 500 and DNA 1000 assays using the Agilent 2100 bioanalyzer showed a lower percentage error and a better reproducibility as compared to those obtained by the conventional method. Conclusion: Based on the performance of the bioanalyzer, we suggest that this novel Labchip is adequate to replace the current RFLP analysis by the agarose gel electrophoresis for mtDNA mutation detection. (C) 2002 Elsevier Science B.V. All rights reserved.
\end{abstract}

Keywords: Labchip; mtDNA mutation; RFLP; Mitochondrial disease

\section{Introduction}

Mitochondria are the power plant of the cells and the only organelles that contain extra-chromosomal DNA. Human mitochondrial DNA (mtDNA) is 16569 bp in size and encodes seven subunits of NADH: ubiquinone oxidoreductase (Complex I), one subunit of ubiquinol: cytochrome $c$ oxidoreductase (Complex

\footnotetext{
* Corresponding author. Tel.: +886-2-2826-7118; fax: +886-22826-4843.

E-mail address: joeman@mailsrv.ym.edu.tw (Y.-H. Wei).
}

III), three subunits of cytochrome $c$ oxidase (Complex IV), and two subunits of $\mathrm{F}_{1} \mathrm{~F}_{\mathrm{o}}$-ATPase, along with 22 tRNAs and 2 rRNAs essential for their translation [1]. The remaining mitochondrial respiratory proteins are encoded by nuclear DNA, translated in the cytoplasm, and then imported into mitochondria where they are assembled into functional complexes together with the mtDNA-encoded polypeptides [2].

A number of human diseases are caused by the inherited mtDNA mutations, which primarily affect the muscle and brain tissues. The clinical severity increases with age and with the proportion of the mutant mtDNA 
(A)

(B)

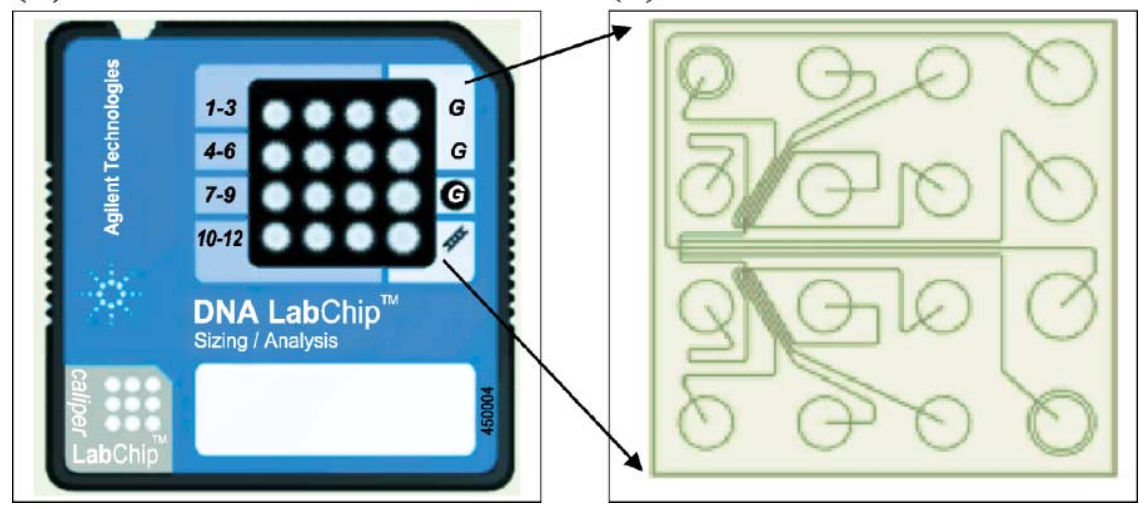

Fig. 1. The DNA Labchip used in the Agilent 2100 bioanalyzer. The chip is designed to perform manipulations such as dispensing, mixing, incubation, reaction, sample partition, and detection. (A) Each chip contains 16 wells: 3 for loading of the gel-dye mixture, 1 for the molecular size ladder, and 12 for experimental samples. (B) The chip architectures consist of interconnected microchannels made by semiconductor-like microfabrication techniques. DNA size separation can be performed inside the microchannels, which are filled with a sieving polymer and fluorescence dye. The movement of DNA within fluids through the microchannels is effected by electrodes, which create electrokinetic forces capable of driving fluids and DNA molecules. Automated regulation of voltage between these electrodes controls the speed and direction of the fluid movements. As the electrical voltage is applied, DNA fragments of different sizes intercalating with the fluorescent dye are separated according to their mass and can be detected by a laser-based detector.

(A)

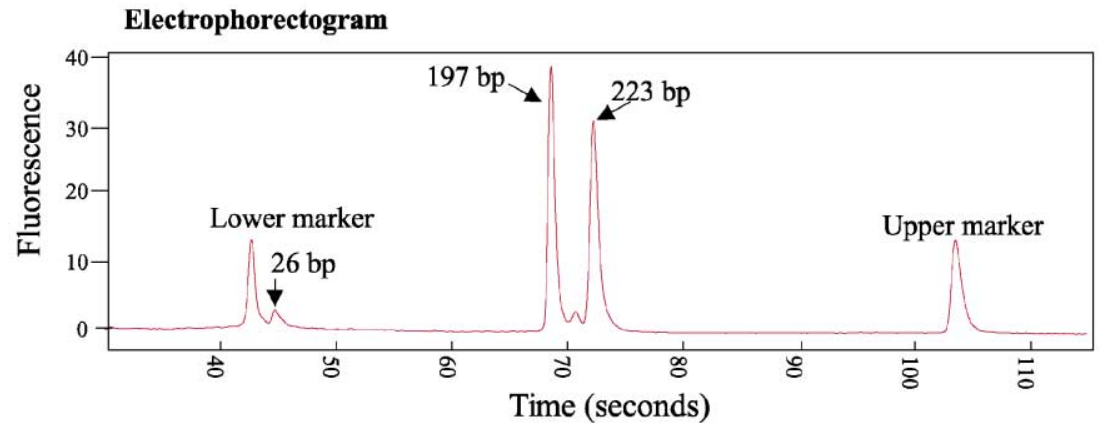

(B) MERRF Chen family

\begin{tabular}{|c|c|c|}
\hline Peak & $\begin{array}{l}\text { Mig.Time } \\
\text { (secs) }\end{array}$ & Corr.Area \\
\hline 1 & 37.3 & 0.16 \\
\hline 2 & 42.7 & 21.66 \\
\hline 3 & 44.7 & 4.63 \\
\hline 4 & 68.6 & 40.44 \\
\hline 5 & 70.7 & 3.49 \\
\hline 6 & 72.3 & 39.13 \\
\hline 7 & 103.5 & 13.84 \\
\hline
\end{tabular}

Sample 8

Size(BP) Conc. Molarity Marker

(bp) $\quad(\mathrm{ng} / \mathrm{ul}) \quad(\mathrm{nmol} / \mathrm{l})$

$15 \quad 4.2 \quad 424.24 \quad$ Lower

26

1.0

67.90

47.01

3.72

39.26

$5.30 \quad$ Upper

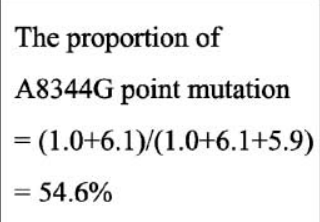

Fig. 2. (A) The electrophoretogram shows the result of a RFLP analysis of the PCR product containing the A8344G mtDNA mutation by the Agilent 2100 bioanalyzer in the MERRF patients. The 223-bp DNA fragment represents the wild-type PCR product and the 197- and 26-bp fragments represent the mutant-type PCR products. DNA lower marker was used to align the electropherogram. The upper marker was used for the determination of the DNA concentration. (B) The bioanalyzer 2100 software performs automated peak identification, and the size and concentration of DNA are presented in a digital format. The amounts of the mutant mtDNA and wild-type mtDNA (uncut) fragments were respectively estimated by the determination of the peak area of each DNA fragment. 
present in the affected tissues [3-5]. Two of these diseases, MELAS (mitochondrial myopathy, encephalopathy, lactic acidosis, and stroke-like episodes) and MERRF (myoclonic epilepsy and ragged-red fibers) syndromes, are caused mostly by point mutations in the tRNA genes of mtDNA. The patients with MELAS syndrome have an $A \rightarrow G$ transition at the nucleotide position 3243 in the tRNA ${ }^{\text {Leu (UUR) }}$ gene $[5,6]$ and the MERRF patients harbor an $\mathrm{A} \rightarrow \mathrm{G}$ mutation at nucleotide position 8344 in the tRNA ${ }^{\text {Lys }}$ gene $[7,8]$.

The conventional diagnosis of mitochondrial diseases is based on clinical symptoms and histochemical studies of mitochondrial abnormalities in the skeletal muscles. This is difficult because of the diversity of the clinical manifestations and histopathological studies of the muscle biopsies sometimes fail to reveal the pathological changes such as ragged-red fibers. With the rapid advances of molecular biology, mutation analysis of mtDNA has provided useful information for a definitive diagnosis of many mitochondrial diseases.

We evaluated the Agilent 2100 bioanalyzer (Agilent Technologies, Palo Alto, CA) for the detection of the DNA mutations associated with mitochondrial diseases. The bioanalyzer represents a new generation of capillary electrophoresis (CE) instruments for the nucleic acid separation based on microfluidics. It is the first commercially available chip that was designed to rapidly analyze DNA fragments without the need of specialized electrophoresis equipment and the space for operation. Currently, four DNA Labchip kits are available from Agilent, which include DNA 500, DNA 1000, DNA 7500, and DNA 12000 to size a broad range of DNA fragments from 25 to $12000 \mathrm{bp}$. Through the use of microfluidic technology, 12 DNA samples can be sized and quantified on a disposable chip (Fig. 1A) within $30 \mathrm{~min}$. The Labchip system is fabricated from a piece of glass and comprises an interconnected network of microchannels filled with a sieving polymer and a fluorescent dye (Fig. 1B). The movement of DNA molecules through the microchannels is controlled by a series of electrodes, each of which is independently connected to a power supply. As an electrical voltage is applied, DNA molecules of different sizes intercalating with dye are separated according to their mass and can be detected by a laser-induced detector. Agilent 2100 bioanalyzer software allows real-time analysis of the results and the automated digital data processing. The fragment size and concentration of DNA can be displayed in both the electrophoretogram and gel-like image formats. The relative proportion of the mutant mtDNA can be estimated by determining the peak areas in the chromatogram of the DNA fragments amplified from both the mutant and wild-type mtDNA (Fig. 2). The software is configured for easy data storage and retrieval, offering the flexibility to compare results generated from different samples.

Several applications of the bioanalyzer system have been published [9-12]. Smith et al. [9] used the Agilent 2100 bioanalyzer to detect telomerase expressed in the prostatic fluid of patients being evaluated for prostate cancer. Prostate cancer is curable if it is diagnosed and treated at an early stage. Therefore, early detection is crucial and the Agilent 2100 bioanalyzer can provide useful information in this arena. Moreover, for the typing of Campylobacter jejuni, Nachamkin et al. [10] compared the results obtained by the Labchip kit with those by the conventional agarose gel electrophoresis after the restriction enzyme digestion of the flagellin gene. They found that some improvements in the chip are needed and that the bioanalyzer has the potential to replace the conventional RFLP analysis of the DNA mutation by the agarose gel electrophoresis.

We previously developed a method for the detection of the DNA mutation associated with mitochondrial diseases based on the PCR-RFLP analysis [13-15]. This method works well and has been routinely used for the diagnosis of many mitochondrial diseases. The only drawback is the need to use an isotope for the quantitative determination of the mutated mtDNA. Thus, it is appealing to simplify the use of existing methods for the detection of the mtDNA mutation. To replace the current analytical gel electrophoresis used in the detection of most mtDNA mutation, we compared the sizing and quantification accuracy between the Labchip system and the conventional agarose gel electrophoresis.

\section{Materials and methods}

\subsection{Subjects}

Three members of a family with MELAS syndrome and four members of a family with MERRF syndrome were recruited in this study. 
The proband with MELAS syndrome (III-5 in Fig. 3) suffered from the progressive muscle weakness within the past year and exhibited a right focal seizure. A muscle biopsy showed ragged-red fibers on the modified Gomori trichrome stain. We performed an evaluation on the proband's mother and found that she had diabetes mellitus and had been under diet control.

The 15-year-old patient with MERRF syndrome (IV-1 in Fig. 4) had poor learning since early childhood, unsteady gait with tremor or intermittent myoclonus since 12 years of age, and myoclonic epilepsy since 1998. Her maternal side had strong history of mitochondrial disorder. Three elder sisters of her grandmother (II-1, II-2, II-3) had symptoms similar to those of the proband; one died recently and two died at 10-20 years of age. Two sisters of her mother (III-11, III-12) and two female cousins (IV-4, IV-5) also had similar symptoms.

\subsection{DNA isolation}

Blood, hair follicles, and/or skin biopsies were obtained with consent from the members of the patient's families with MERRF and MELAS syndrome, respectively. Total DNA was isolated directly from the blood cells, hair follicles, and/or skin biopsies according to the methods described previously [13].

\subsection{Polymerase chain reaction}

For the detection of $\mathrm{A} 3243 \mathrm{G}$ mutation of mtDNA, a 1159-bp DNA fragment was amplified by the polymerase chain reaction (PCR) from the normal and the mutated mtDNA molecules using the forward primer L2678: 5' -ATTGACCTGCCCGTGAAGA-3' and reverse prime H3836: 5' -GGCAGGAGTAATCAGAGGTG-3'). Amplification was done for 30 cycles and the thermal profile consisted of $15 \mathrm{~s}$ of denaturation of the DNA at $94^{\circ} \mathrm{C}, 15 \mathrm{~s}$ of annealing of the DNA with primers at $58^{\circ} \mathrm{C}$, and $40 \mathrm{~s}$ of primer extension at $72^{\circ} \mathrm{C}$ using a GeneAmp 9700 PCR System (PerkinElmer/Cetus, Norwalk, CT). In the last cycle of PCR, 5 $\mu \mathrm{Ci}$ of $\left[\alpha-{ }^{33} \mathrm{P}\right]$-dATP was added to the reaction mixture to label the PCR products. An aliquot of $10 \mu \mathrm{l}$ of the PCR products was digested overnight at $30^{\circ} \mathrm{C}$ with 10 units of the restriction enzyme $A p a \mathrm{I}$, which recognizes the sequence GGGCCC resulting from the A3243G mutation. The mtDNA fragment harboring the A $3243 \mathrm{G}$ mutation generated two additional fragments of 591 and $568 \mathrm{bp}$, respectively. The Apa I-digested PCR products were then subjected to electrophoresis on a $3 \%$ agarose gel at $100 \mathrm{~V}$ for $2 \mathrm{~h}$. After electrophoresis, the gel was dried and subjected to autoradiography. The X-ray film was then scanned with a scanning densitometer (Personal Densitometer SI, Molecular Dynamics, Sunnyvale, CA). The proportions of the mutant DNA and wild-type DNA (uncut) fragments were respectively estimated by determining the ratio of their intensities in the negative film [14].

To detect the A8344G mutation, a segment of mtDNA was amplified by PCR, using a forward primer L8150 (8150-8169): 5' -CCGGGGGTATACTACGGTCA-3' and a mismatched primer MR28 (8372-8345) containing two nucleotides different from the Cambridge sequence, 5' -GGGGCATTTCACTGTAAAGAGGTGCCGG-3', as a reverse primer. These mismatches were especially designed to create a Nae I recognition site after the amplification of the DNA segment encompassing the putative A8344G point mutation in mtDNA of the MERRF patients. The 223-bp PCR product could be cleaved by Nae I into 197- and 26-bp fragments and the digested DNA mixture was further processed and analyzed as described earlier [15].

\subsection{Chip preparation}

DNA 500 and DNA 1000 Labchips (Agilent Technologies) were used in this study for the detection of the proportion of mtDNA with $\mathrm{A} 3243 \mathrm{G}$ and $\mathrm{A} 8344 \mathrm{G}$ mutations, respectively. Briefly, microchannels were filled by pipetting $9 \mu \mathrm{l}$ of the gel-dye mixture into the appropriate well and then forced the mixture into the microchannels by applying pressure to the well via a $1-\mathrm{ml}$ syringe. The ladder well and sample wells were subsequently loaded with $5 \mu \mathrm{l}$ of the DNA size marker mixture plus $1 \mu \mathrm{l}$ of either the molecular size ladder or sample. After mixing by vortex, the chips were immediately inserted into the bioanalyzer and processed according to the instructions of the manufacturer. The amount of the A8344G mutant DNA was determined by the relative ratio of the areas of the two peaks of the mutant and wild-type DNA fragments in the chromatogram (Fig. 2). 


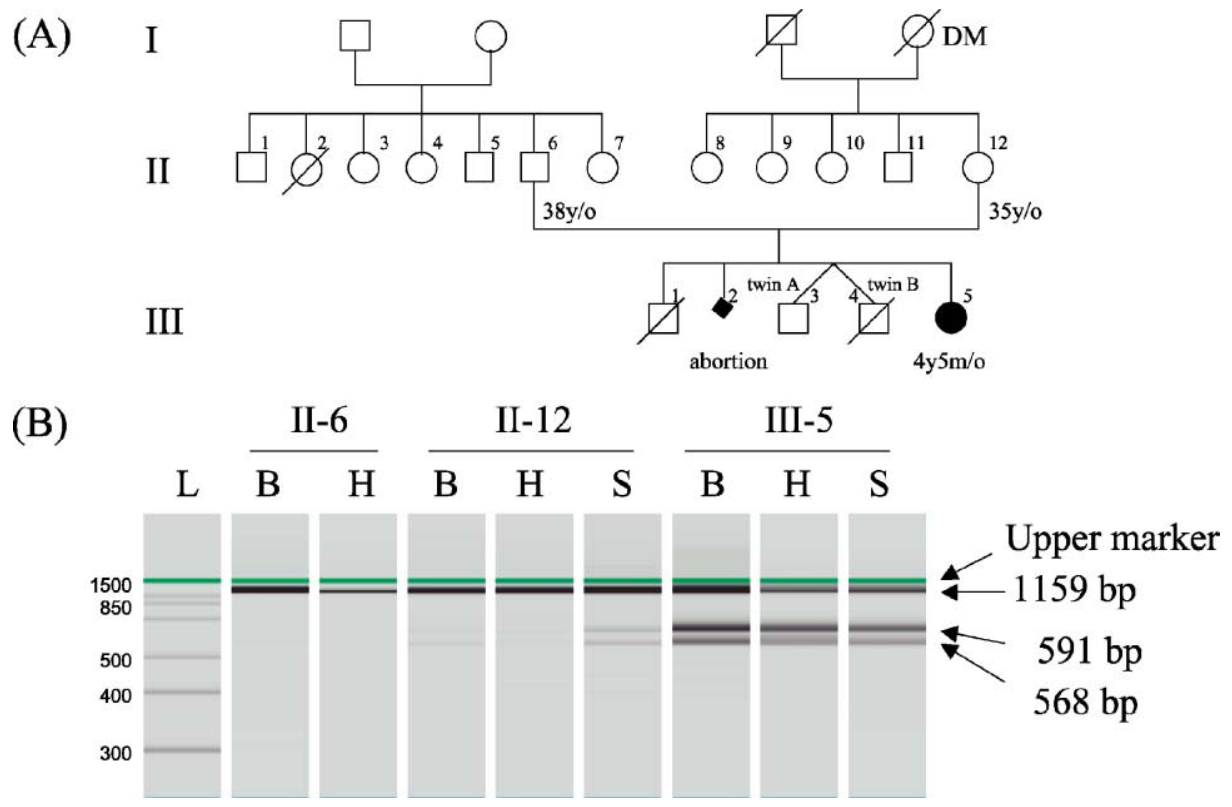

Fig. 3. (A) Outline of the two-generation pedigree from the MELAS family investigated in this study. Filled circle indicates the proband, open symbols indicate the asymptomatic family members. (B) Restriction analyses by the Agilent 2100 bioanalyzer for the presence of mtDNA with the A3243G mutation in various tissues of the proband. A 1159-bp PCR product was cleaved into two fragments (591 and $568 \mathrm{bp)}$ from the DNA samples of members II-6, II-12, and III-5 of the family (L, marker; B, blood; H, hair follicles; S, skin fibroblasts).

(A) I

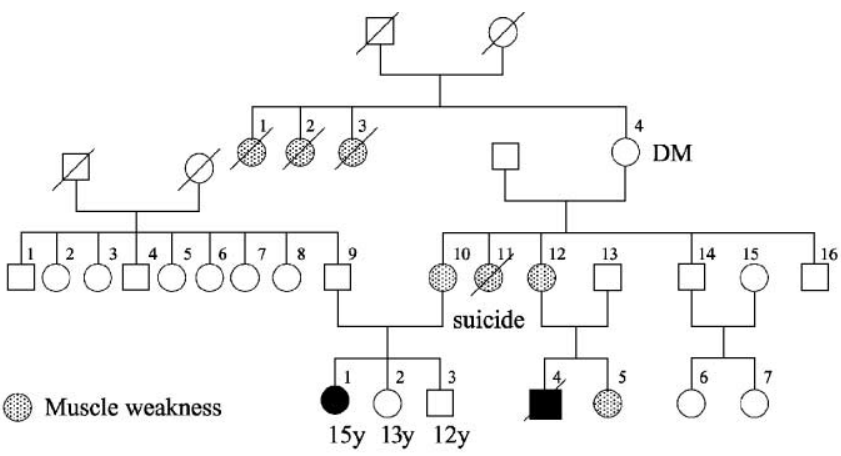

(B)

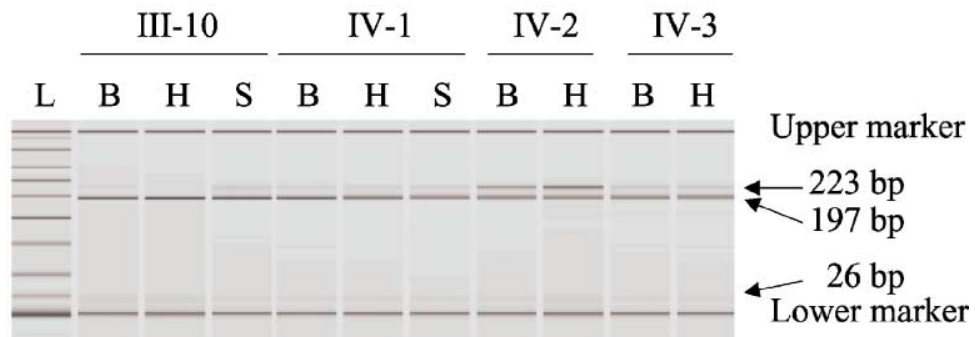

Fig. 4. (A) Outline of the four-generation pedigree from a MERRF family investigated in this study. Filled circle indicates the proband and open symbols indicate the asymptomatic family members. (B) Restriction analyses by the Agilent 2100 bioanalyzer for the existence of mtDNA with the A8344G mutation in various tissues of the proband. A 223-bp PCR product was cleaved into two fragments (197 and $26 \mathrm{bp}$ ) from the DNA samples of the members III-10, IV-1, IV-2, and IV-3 of this family (L, marker; B, blood; H, hair follicles; S, skin fibroblasts). 


\section{Results and discussion}

The genotype characteristics of the three members in two generations of the family with MELAS syndrome and members in two generations of the family with MERRF syndromes were fully investigated and clinically confirmed.

After the digestion of the PCR products of mtDNA with Apa I, we detected three fragments including the undigested 1159 bp DNA fragment and two fragments (591 and $568 \mathrm{bp}$ ) generated from the $\mathrm{A} 3243 \mathrm{G}$ mutant mtDNA in the blood, hair follicles, and skin biopsies of the proband and members of the MELAS family (Fig. 3). To determine the sizing accuracy and reproducibility, all the samples from the three members of the family with MELAS syndrome were amplified by PCR and the products were digested by Apa I and analyzed by the agarose gel electrophoresis and by the DNA 1000 chips three times, respectively. To examine the well-to-well and chip-to-chip variations, the Apa I-digested PCR products from eight samples were applied to the DNA 1000 chips for analysis and the sizes of three fragments are shown in Table 1.

Moreover, we also analyzed the A8344G mutation of the four members of the MERRF family. The gel image revealed three fragments including the wildtype 223-bp fragments and two newly generated fragments of 197 and $23 \mathrm{bp}$ after the PCR products of mtDNA had been digested with Nae I. To determine the well-to-well and chip-to-chip variations, all the samples from the four members of the family with MERRF syndrome were amplified by PCR and the products were digested by Nae I and analyzed four

Table 1

Sizing accuracy in the restriction analysis of the mtDNA fragment containing the $\mathrm{A} 3243 \mathrm{G}$ point mutation

\begin{tabular}{|c|c|c|c|c|c|c|}
\hline \multicolumn{7}{|c|}{ Chips DNA 1000 assay } \\
\hline \multirow[t]{2}{*}{$\begin{array}{l}\text { Size of DNA } \\
\text { fragment }\end{array}$} & \multicolumn{3}{|c|}{$\begin{array}{l}\text { Same chips } \\
\text { ( } 8 \text { wells) }\end{array}$} & \multicolumn{3}{|c|}{$\begin{array}{l}\text { Different chips } \\
\text { ( } 3 \text { chips) }\end{array}$} \\
\hline & $\begin{array}{l}\text { Size from } \\
\text { chip (bp) }\end{array}$ & S.D. & $\begin{array}{l}\text { Error } \\
(\%)\end{array}$ & $\begin{array}{l}\text { Size from } \\
\text { chip (bp) }\end{array}$ & S.D. & $\begin{array}{l}\text { Error } \\
(\%)\end{array}$ \\
\hline 1159 & 1175 & 14 & 1.35 & 1185 & 10 & 2.14 \\
\hline 591 & 640 & 5 & 8.26 & 642 & 2 & 8.56 \\
\hline 568 & 572 & 5 & 0.67 & 576 & 3 & 1.28 \\
\hline
\end{tabular}

times by the agarose gel electrophoresis and by the DNA 500 and DNA 1000 chips four times, respectively. The sizing reproducibility and accuracy of the three fragments determined in the DNA 500 chip and DNA 1000 chip are shown in Table 2.

We observed low-level well-to-well variations $(<14 \mathrm{bp})$ in the detection of A3243G mutation $(<1$ bp of DNA 500 and $<2$ bp of DNA 1000) and in the detection of $\mathrm{A} 8344 \mathrm{G}$ mutation of mtDNA. On the other hand, we found that the chip-to-chip variation was below $10 \mathrm{bp}$ in the detection of A3243G point mutation and 1-2 bp variations for the DNA 500 and DNA 1000 in the detection of the A8344G point mutation. The data generated with the Labchip kit showed a low percentage error and good reproducibility. Such high sizing accuracy was achieved with the Agilent 2100 bioanalyzer by including the external sizing standards in the ladder wells and internal standards for the mass and size markers in each lane.

On the other hand, eight samples were also subjected to three PCR-RFLP analyses in triplicate using the DNA 1000 chip sets and the gel patterns were compared with those obtained from the 3\% agarose gel when the PCR product was labeled with an isotope for the analysis of the proportion of the mutated mtDNA in the MELAS family. Fig. 3 shows the proportions of mtDNA with the A3243G mutation in the blood cells, hair follicles, and skin fibroblasts of the proband and her mother of the MELAS family. The proband's father (II-6) did not carry the A3243G mutation in the blood cells or hair follicles. The proportions of mtDNA with the A3243G mutation were determined by the DNA 1000 chip and the agarose gel electrophoresis with an isotope labeling of the mtDNA fragments and the results are summarized in Table 3. Comparison of the results from the analysis by the DNA 1000 chip revealed that the samples containing a less mutated mtDNA showed a higher proportion of the mutated mtDNA when determined by the agarose gel electrophoresis with an isotope labeling. For the quantification of the proportion of mtDNA with the A3243G point mutation, we found that the variation for the Labchip 1000 was low $(<6.2 \%$ in the different PCR reactions and $<5 \%$ in different chips at the same PCR reaction) as compared with the agarose gel analysis with an isotope labeling $(<26.9 \%$ for the 
Table 2

Sizing accuracy in the restriction analysis of mtDNA fragment containing the A8344G point mutation

\begin{tabular}{|c|c|c|c|c|c|c|c|c|c|c|c|c|}
\hline \multirow[b]{3}{*}{$\begin{array}{l}\text { Size } \\
\text { (bp) }\end{array}$} & \multicolumn{6}{|c|}{ DNA 500 Chip } & \multicolumn{6}{|c|}{ DNA 1000 Chip } \\
\hline & \multicolumn{3}{|c|}{ Same chips (10 wells) } & \multicolumn{3}{|c|}{ Different chips (4 chips) } & \multicolumn{3}{|c|}{ Same chips (10 wells) } & \multicolumn{3}{|c|}{ Different chips (4 chips) } \\
\hline & $\begin{array}{l}\text { Size } \\
\text { (bp) }\end{array}$ & S.D. & $\begin{array}{l}\text { Error } \\
(\%)\end{array}$ & $\begin{array}{l}\text { Size } \\
\text { (bp) }\end{array}$ & S.D. & $\begin{array}{l}\text { Error } \\
(\%)\end{array}$ & $\begin{array}{l}\text { Size } \\
\text { (bp) }\end{array}$ & S.D. & $\begin{array}{l}\text { Error } \\
(\%)\end{array}$ & $\begin{array}{l}\text { Size } \\
\text { (bp) }\end{array}$ & S.D. & $\begin{array}{l}\text { Error } \\
(\%)\end{array}$ \\
\hline 223 & 226 & 1 & 1.12 & 226 & 1 & 1.35 & 228 & 1 & 2.02 & 230 & 2 & 3.05 \\
\hline 197 & 197 & 1 & 0.20 & 198 & 1 & 0.63 & 198 & 1 & 0.60 & 200 & 2 & 1.47 \\
\hline 26 & 23 & 0 & 11.50 & 23 & 0 & 11.50 & 22 & 0 & 15.40 & 22 & 1 & 15.00 \\
\hline
\end{tabular}

Table 3

Accuracy for the quantitative determination of mtDNA with the A3243G point mutation

\begin{tabular}{|c|c|c|c|c|c|}
\hline \multirow[t]{3}{*}{ Subject } & \multirow[t]{3}{*}{ Tissue } & \multicolumn{4}{|c|}{ Proportion of mtDNA with A3243G point mutation (\%) } \\
\hline & & \multicolumn{2}{|c|}{ Analysis by DNA 1000} & \multicolumn{2}{|c|}{ Analysis by isotope-labeling } \\
\hline & & $\begin{array}{l}\text { Different reactions } \\
(n=3)\end{array}$ & $\begin{array}{l}\text { Same reactions } \\
(n=3)\end{array}$ & $\begin{array}{l}\text { Different reactions } \\
(n=3)\end{array}$ & $\begin{array}{l}\text { Same reaction, different } \\
\text { exposure time }(n=3)\end{array}$ \\
\hline \multirow[t]{3}{*}{ II-12 } & $\mathrm{B}$ & $1.9 \pm 0.2$ & $2.0 \pm 0.2$ & $8.1 \pm 2.6$ & $5.8 \pm 1.6$ \\
\hline & $\mathrm{H}$ & $0.6 \pm 0.1$ & $0.6 \pm 0.1$ & $2.6 \pm 1.0$ & $2.7 \pm 0.9$ \\
\hline & $\mathrm{S}$ & $4.7 \pm 0.1$ & $4.8 \pm 0.2$ & $14.7 \pm 2.7$ & $10.8 \pm 3.4$ \\
\hline \multirow[t]{3}{*}{ IIII-5 } & $\mathrm{B}$ & $34.1 \pm 1.4$ & $33.2 \pm 0.1$ & $36.1 \pm 7.7$ & $27.2 \pm 8.0$ \\
\hline & $\mathrm{H}$ & $62.9 \pm 6.2$ & $65.8 \pm 5.1$ & $60.0 \pm 26.9$ & $33.0 \pm 8.2$ \\
\hline & $\mathrm{S}$ & $54.4 \pm 2.6$ & $55.7 \pm 1.8$ & $55.3 \pm 24.7$ & $31.5 \pm 8.2$ \\
\hline
\end{tabular}

B, blood; H, hair follicles; S, skin fibroblast.

different PCR reactions and $<8.2 \%$ for the different times of exposure to the same PCR reaction products). The reproducibility of the DNA 1000 chip was better than that of the agarose gel electrophoresis of an isotope-labeled mtDNA fragments. It is worth noting that the different exposure times may affect the intensity of the X-ray film and may cause variations in the proportion of the mutated mtDNA. The exposure time of an isotope-labeled mtDNA fragments is the most important factor affecting the accuracy of the quantitative analysis of the mtDNA mutation by the agarose gel electrophoresis. In con-

Table 4

Quantification accuracy for the quantitative determination of mtDNA with A8344G point mutation

\begin{tabular}{|c|c|c|c|c|c|}
\hline \multirow[t]{3}{*}{ Subject } & \multirow[t]{3}{*}{ Tissue } & \multicolumn{4}{|c|}{ Proportion of mtDNA with A8344G point mutation (\%) } \\
\hline & & \multicolumn{2}{|l|}{ DNA 500} & \multirow{2}{*}{$\frac{\text { DNA } 1000}{\text { Same reactions }}$} & \multirow{2}{*}{$\frac{\text { Isotope-Labelling }}{\text { Different reactions }}$} \\
\hline & & Different reactions & Same reactions & & \\
\hline \multirow[t]{3}{*}{ III-10 } & $\mathrm{B}$ & $88.1 \pm 2.5$ & $89.3 \pm 0.3$ & $85.1 \pm 0.7$ & $61.0 \pm 3.1$ \\
\hline & $\mathrm{H}$ & $93.9 \pm 0.7$ & $94.1 \pm 0.4$ & $89.8 \pm 0.1$ & $61.3 \pm 2.1$ \\
\hline & $\mathrm{S}$ & $79.3 \pm 2.0$ & $79.5 \pm 0.2$ & $76.5 \pm 0.2$ & $47.6 \pm 6.0$ \\
\hline \multirow[t]{3}{*}{ IV-1 } & $\mathrm{B}$ & $83.5 \pm 2.7$ & $84.0 \pm 0.1$ & $79.8 \pm 0.1$ & $48.4 \pm 4.1$ \\
\hline & $\mathrm{H}$ & $88.3 \pm 2.3$ & $88.1 \pm 0.2$ & $85.4 \pm 0.1$ & $50.9 \pm 4.7$ \\
\hline & $\mathrm{S}$ & $85.2 \pm 2.8$ & $84.6 \pm 0.1$ & $81.9 \pm 0.1$ & $56.4 \pm 5.5$ \\
\hline \multirow[t]{2}{*}{ IV-2 } & $\mathrm{B}$ & $63.7 \pm 2.8$ & $63.4 \pm 0.3$ & $60.2 \pm 0.2$ & $42.0 \pm 8.0$ \\
\hline & $\mathrm{H}$ & $54.4 \pm 3.3$ & $53.7 \pm 0.2$ & $51.6 \pm 0.3$ & $46.6 \pm 6.3$ \\
\hline \multirow[t]{2}{*}{ IV-3 } & B & $80.8 \pm 3.4$ & $81.8 \pm 0.4$ & $76.8 \pm 0.3$ & $52.2 \pm 5.3$ \\
\hline & $\mathrm{H}$ & $83.3 \pm 3.0$ & $83.0 \pm 0.1$ & $79.9 \pm 0.1$ & $56.8 \pm 8.2$ \\
\hline
\end{tabular}

B, blood; $\mathrm{H}$, hair follicles; S, skin fibroblasts. 
trast to the isotope-labeling and RFLP method, the data obtained by the Agilent bioanalyzer showed good reproducibility.

Fig. 4 shows the A8344G mutation in the blood cells, hair follicles, and skin biopsies of the proband and her family members. For the analysis of the proportion of the mutated mtDNA in the MERRF family, 10 samples were subjected to the PCR amplification for three times in the DNA 500 and DNA 1000 chip kits and the patterns were compared with those obtained from the 3\% agarose gel electrophoresis of the PCR products labeled with an isotope. To compare the performance between DNA 500 and DNA 1000 chips, the proportion of mtDNA with the A8344G mutation from the blood cells, hair follicles, and skin fibroblasts in the members III-10, IV-1, IV-2, and IV-3 were analyzed by the two chips and the agarose gel electrophoresis of the products from three PCR reactions or from the same PCR reaction (Table 4). In the quantification of the proportion of the A8344G mutated mtDNA, the variation of the results obtained by the Labchip DNA 500 and DNA 1000 kits was lower than that observed in the agarose gel electrophoresis of an isotope-labeled PCR products. The performance of the bioanalyzer is thus superior to the agarose gel analysis.

In summary, the Agilent 2100 bioanalyzer is better than the conventional agarose gel electrophoresis and is thus adequate to replace the current system for the quantitative analysis of the mtDNA mutations. In the case of mitochondrial diseases, there are $>100$ mtDNA mutations and each disease may be associated with one or several types of mtDNA mutation. Accurate and quick determination of the mtDNA mutation(s) specific to a mitochondrial disease is very important for both the clinical diagnosis and therapy of the mitochondrial diseases. The analyses of the mtDNA mutation by the agarose gel with an isotope incorporation into the DNA fragments are time consuming and labor intensive. In this era of highthroughput molecular diagnosis, we have found that the bioanalyzer is easy to use, time and cost effective for the sizing and quantification of the mtDNA mutation in various specimens from the patients with mitochondrial diseases. This system will be useful for an accurate final diagnosis of mitochondrial diseases by the molecular analysis of the specific mtDNA mutations.

\section{Acknowledgements}

This work was supported by grants from the National Science Council (NSC90-2320-B010-079), the National Health Research Institutes (NHRI-GTEX89S505L), and the Ministry of Education (89-BFA22-2-4), the Republic of China. The Agilent 2100 bioanalyzer was kindly provided by Agilent Technologies, Taiwan.

\section{References}

[1] Anderson S, Bankier AT, Barrell BG, de Bruijn MHL, Coulson $\mathrm{AR}$, Drouin J, et al. Sequence and organization of the human mitochondrial genome. Nature 1981;290:457-65.

[2] Wallace DC. Mitochondrial genetics: a paradigm for aging and degenerative diseases? Science 1992;256:628-32.

[3] Wallace DC. Mitochondrial DNA sequence variation in human evolution and disease. Proc Natl Acad Sci U S A 1994; 91:8739-46.

[4] Wallace DC. Mitochondrial DNA variation in human evolution, degenerative disease, and aging. Am J Hum Genet 1995; 57:201-23.

[5] Lestienne P, Bataille N. Mitochondrial DNA alterations and genetic diseases: a review. Biomed Pharmacother 1994;48: 199-214.

[6] Goto Y, Nonaka I, Horai S. A mutation in the tRNA ${ }^{\text {Leu (UUR) }}$ gene associated with the MELAS subgroup of mitochondrial encephalomyopathies. Nature 1990;348:651-3.

[7] Kobayashi Y, Momoi MY, Tominaga K, Momoi T, Nihei K, Yanagisawa $\mathrm{M}$, et al. A point mutation in the mitochondrial tRNA $^{\text {Leu (UUR) }}$ gene in MELAS (mitochondrial myopathy, encephalopathy, lactic acidosis and stroke-like episodes). Biochem Biophys Res Commun 1990;173:816-22.

[8] Shoffner JM, Lott MT, Lezza AMS, Seibel P, Ballinger SW, Wallace DC. Myoclonic epilepsy and ragged-red fiber disease (MERRF) is associated with a mitochondrial DNA tRNA ${ }^{\text {Lys }}$ mutation. Cell 1990;61:931-7.

[9] Smith S, Fuller R, Crocitto L. Agilent 2100 bioanalyzer replaces gel electrophoresis in prostate cancer research. Application Bulletin. Agilent Technologies; Palo Alto, CA, 2000.

[10] Nachamkin I, Panaro NJ, Li M, Ung H, Yuen PK, Kricka LJ, Wilding P. Agilent 2100 bioanalyzer for restriction fragment length polymorphism analysis of the Campylobacter jejuni flagellin gene. J Clin Microbiol 2001;39:754-7.

[11] Panaro NJ, Yuen PK, Sakazume T, Fortina P, Kricka LJ, Wilding P. Evaluation of DNA fragment sizing and quantification by the Agilent 2100 bioanalyzer. Clin Chem 2000;46: 1851-3.

[12] Bousse L, Mouradian S, Minalla A, Yee H, Williams K, Dubrow R. Protein sizing on a microchip. Anal Chem 2001;73: 1207-12.

[13] Shih KD, Yen TC, Pang CY, Wei YH. Mitochondrial DNA mutation in a Chinese family with myoclonic epilepsy and 
ragged-red fiber disease. Biochem Biophys Res Commun 1991;174:1109-16.

[14] Huang CC, Chen RS, Chen CM, Wang HS, Lee CC, Pang CY, et al. MELAS syndrome with mitochondrial tRNA ${ }^{\text {Leu (UUR) }}$ gene mutation in a Chinese family. J Neurol, Neurosurg Psychiatry $1994 ; 57: 586-9$.
[15] Fang W, Huang CC, Chu NS, Lee CC, Chen RS, Pang CY, et al. Myoclonic epilepsy with ragged-red fibers (MERRF) syndrome: report of a Chinese family with mitochondrial DNA point mutation in tRNA ${ }^{\text {Lys }}$ gene. Muscle Nerve 1994; 17:52-7. 